\title{
Comparative Studies on the Interaction of Human and Bovine Serum Albumins with Vitamin C
}

\author{
Husain Alsamamra*, Sawsan Abusharkh, Musa Abuteir \\ Department of Physics, Al-Quds University, Jerusalem, Palestine \\ Email address: \\ hsamamra@staff.alquds.edu (H. Alsamamra) \\ ${ }^{*}$ Corresponding author \\ To cite this article: \\ Husain Alsamamra, Sawsan Abusharkh, Musa Abuteir. Comparative Studies on the Interaction of Human and Bovine Serum Albumins with \\ Vitamin C. European Journal of Biophysics. Vol. 6, No. 1, 2018, pp. 17-22. doi: 10.11648/j.ejb.20180601.13
}

Received: March 25, 2018; Accepted: April 3, 2018; Published: May 11, 2018

\begin{abstract}
The interactions of human and bovine serum albumins (HSA and BSA) with various drugs using spectroscopic techniques have received great attention now a days due to their significant effect in the biomedical field. UV absorption and fluorescence spectroscopy are the most likable due to its high sensitivity and simplicity. The interaction of HSA and BSA with vitamin $\mathrm{C}$ was investigated. Results showed that the absorption and fluorescence intensities increased as the vitamin $\mathrm{C}$ concentration increases. The calculated binding constant $\left(\mathrm{k} \sim 10^{4} \mathrm{M}^{-1}\right)$ showed a week binding of vitamin $\mathrm{C}$ with both serum albumins. The analysis of fluorescence quenching for HSA/BSA-vitamin $\mathrm{C}$ interaction $\left(\mathrm{k}_{\mathrm{q}} \sim 10^{11} \mathrm{~L} \mathrm{~mol}^{-1} \mathrm{~s}^{-1}\right)$ reveals the dynamic quenching process and clearly confirms the existence of static mechanism of fluorescence quenching.
\end{abstract}

Keywords: Vitamin C, Human Serum Albumin, Bovine Serum Albumin, UV-Absorption, Fluorescence Spectroscopy, Binding Constant, Binding Mode

\section{Introduction}

Protein is an important chemical substance in our life and one of the main targets of all medicines in organism. Serum albumins, especially bovine (BSA) and human (HSA), labeled with fluorescent probes are commonly used for the investigation of surface induced conformational changes in protein interfaces [1-3]. From a biopharmaceutical point of view, one of the most important biological functions of albumins is their ability to carry drugs, endogenous and exogenous substances [4]. Both BSA and HSA have very high conformational adaptability to a great variety of ligands [5]. Some groups have studied the in vivo consequences of binding of drugs and other metabolites to serum albumins [68]. Others have examined the binding mechanism using absorption, fluorescence, circular dichroism etc [9-12]. Based on such studies, information on the binding process of many exogenous ligands like long chain fatty acids, amino acids, metals, drugs etc have been reported at the molecular level [13]. HSA and BSA, two of the most extensively studied serum albumins. However, there are still some differences between them [14]. HSA contains a single tryptophan (Trp-
214) [15], while BSA has two tryptophan residues that possess intrinsic fluorescence: Trp-212 is located within a hydrophobic binding pocket of the protein and Trp-134 is located on the surface of the molecule [16]. Therefore, the experimental results of the interaction between drugs and BSA cannot be completely identical with those of HSA.

Therefore, study of the interaction between protein and drug molecules will help provide basic information on the pharmacological actions, bio-transformation, bio-distribution of drugs [17]. The binding phenomena will also be useful to explain the relationship between the structures and functions of proteins. There are some popular techniques which have been used to investigate the interaction between drugs and proteins. UV-absorption and fluorescence spectroscopy are of the powerful techniques to study molecular interactions which changes local environment of fluorophore and helps to predict the binding phenomenon of drugs to proteins [18-21]. There are a number of reports in the literature, where binding of metabolites, drugs, dyes, fatty acids, bio-active-substances have been studied in detail. So the nature of binding of a ligand with HSA (BSA) is different for different ligands [22 25].

Vitamin C or L-ascorbic acid, is an essential nutrient for 
humans and certain other animal species. Vitamin $\mathrm{C}$ refers to a number of vitamins that have vitamin $\mathrm{C}$ activity in animals, including ascorbic acid and its salts, and some oxidized forms of the molecule like dehydroascorbic acid [26]. Vitamin $\mathrm{C}$ is a cofactor in at least eight enzymatic reactions, including several collagen synthesis reactions that, when dysfunctional, cause the most severe symptoms of scurvy [27]. In animals, these reactions are especially important in wound-healing and in preventing bleeding from capillaries [28]. Ascorbate may also act as an antioxidant against oxidative stress. Designated chemically as 2-Oxo-L-threohexono-1,4-lactone-2,3-enediol. The molecular weight is $176.12 \mathrm{~g} / \mathrm{mol}$. Its molecular formula is $\mathrm{C}_{6} \mathrm{H}_{8} \mathrm{O}_{6}$ [29] The structural formula is given in Figure 1:

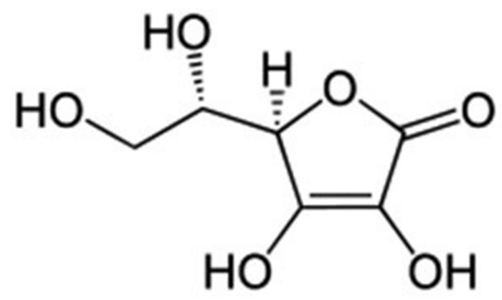

Figure 1. The structure of L-ascorbic acid.

In this work, this paper mainly studied about the interaction of human and bovine serum albumins with vitamin $\mathrm{C}$ using UV-absorption and fluorescence spectroscopic techniques, and to do a comparison between the binding behaviors of both proteins with vitamin $\mathrm{C}$.

\section{Experimental}

\subsection{Chemicals}

HSA and BSA (purity $>99 \%$ ) was purchased from Sigma Aldrich Company, and vitamin $\mathrm{C}$ was purchased from AlQuds Co. pharmaceutical chemical industries, their solutions were prepared in phosphate buffer solutions $(\mathrm{pH}=7.4)$. The other substances are of reagent grade, and were used without further purifications.

A final concentration of $(40 \mathrm{mg} / \mathrm{ml})$ of HSA and BSA was used in the final vitamin C-protein solution, then the solution was placed in ultrasonic water path (SIBATA AU-3T) for one hour to ensure that all the amount of vitamin $\mathrm{C}$ was completely dissolved. The final concentrations of Vitamin CProtein complexes were prepared by mixing equal volumes of HSA and BSA to equal volume from different concentration of vitamins $\mathrm{C}$. HSA and BSA concentrations in all samples kept at $40 \mathrm{mg} \cdot \mathrm{ml}^{-1}$. The final concentrations of the vitamin $C$ are $\left(40,20,10,5,2\right.$ and $\left.1 \mathrm{mg}^{-\mathrm{ml}^{-1}}\right)$. The solution were incubated for $1 \mathrm{~h}$ (at $25^{\circ} \mathrm{C}$ ) before spectroscopic measurements were taken.

\subsection{Apparatus}

UV-VIS spectrophotometer

The absorption spectra were obtained by the use of a NanoDrop ND-1000 spectrophotometer. It is used to measure the absorption spectrum of the samples in the range between $220-750 \mathrm{~nm}$, with high accuracy and reproducibility.

\section{Fluorescence spectrometer}

The fluorescence measurements were performed by a NanoDrop ND-3300 Fluoro-spectrophotometer at $25^{\circ} \mathrm{C}$. The excitation source comes from one of three solid-state light emitting diodes (LEDs). The excitation source options include: UV LED with maximum excitation $365 \mathrm{~nm}$, Blue LED with excitation $470 \mathrm{~nm}$, and white LED from 500 to $650 \mathrm{~nm}$ excitation. A 2048-element CCD array detector covering $400-750 \mathrm{~nm}$, is connected by an optical fiber to the optical measurement surface. The excitation is done at the wavelength of $360 \mathrm{~nm}$ and the maximum emission wavelength is at $439 \mathrm{~nm}$.

The absorption and emission spectra were recorded for free HSA and BSA at 40mg. $\mathrm{ml}^{-1}$ and for its complexes with vitamin $C$ solution with the concentrations of $(40,20,10,5,2$ and $\left.1 \mathrm{mg} \cdot \mathrm{ml}^{-1}\right)$. Repeated measurements were done for all samples.

\section{Results and Discussions}

\subsection{UV Absorption Spectra}

UV-vis absorption measurement is a simple and pertinent method that is used to investigate structural changes and to explore complex formation [30]. To initially verify the quenching mechanism, the UV absorption spectra of HSA-vitamin C and BSA-vitamin C were measured and recorded. As shown in Figure 2, both proteins showed an absorption peak of $268 \mathrm{~nm}$. With the addition of vitamin $\mathrm{C}$, the intensity increased, indicating disturbances to the microenvironment around the amide bonds in the protein. The results demonstrated the existence of an interaction between HSA and BSA with vitamin $C$, this is due to major ligand protein interaction at protein surface which does not limit the mobility of ligand around protein molecule.

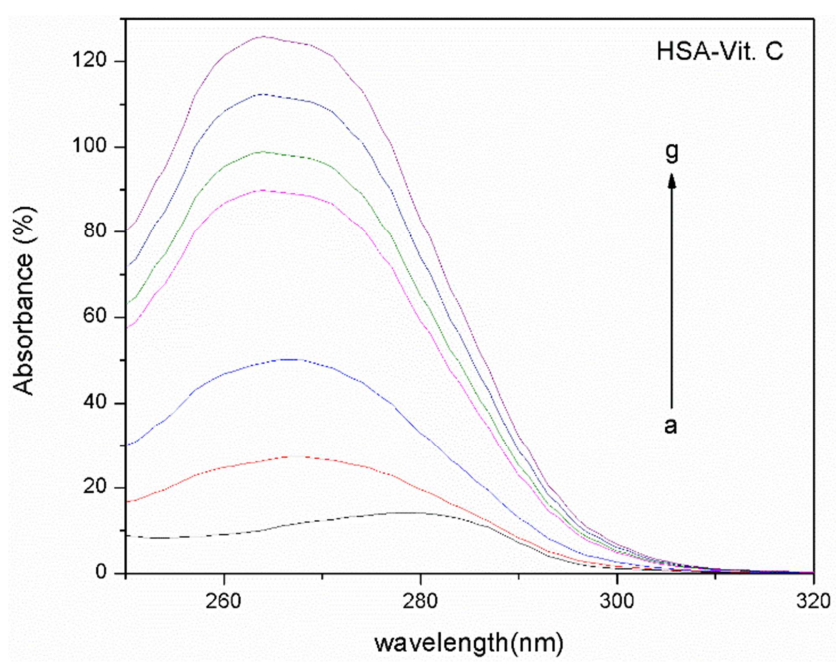

(a) 


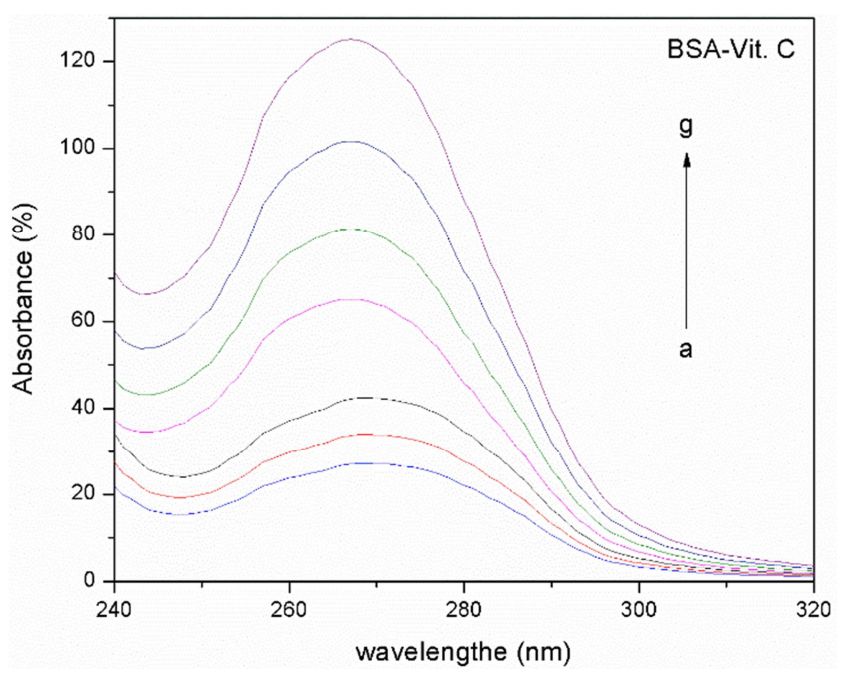

(b)

Figure 2. UV-absorbance spectra of different concentrations of vitamin $C$ (a=free $H S A, \quad b=1 m g \cdot m l^{-1}, \quad c=2 m g \cdot m l^{1}, \quad d=5 m g \cdot m l^{-1}, \quad e=10 m g \cdot m l^{-1}$, $\left.f=20 m g \cdot m l^{-1}, g=40 m g \cdot m l^{-1}\right)$ with $a$. HSA, b. BSA.

The absorption data were treated using linear reciprocal plots based on the following equation [31].

$$
\frac{1}{A-A_{0}}=\frac{1}{A_{\infty}-A_{0}}+\frac{1}{K\left[A_{\infty}-A_{0}\right]} \cdot \frac{1}{L}
$$

where $\mathrm{A}_{0}$ corresponds to the initial absorption of protein at 280 $\mathrm{nm}$ in the absence of ligand, $\mathrm{A}_{\infty}$ is the final absorption of the ligated protein, and $\mathrm{A}$ is the recorded absorption at different vitamin $\mathrm{C}$ concentrations (L). Figure 3 represents the double reciprocal plots of $1 /\left(\mathrm{A}-\mathrm{A}_{0}\right)$ vs. $1 / \mathrm{L}$ for HSA-vitamin $\mathrm{C}$ and BSA-vitamin $\mathrm{C}$ complexes. The binding constant $(\mathrm{K})$ can be estimated from the ratio of the intercept to the slope. The obtained values of the binding constants indicates a relatively weak interaction of vitamin $\mathrm{C}$ with HSA $\left(\mathrm{K}=1.28 \times 10^{4} \mathrm{M}^{-1}\right)$ and with BSA $\left(\mathrm{K}=1.39 \times 10^{4} \mathrm{M}^{-1}\right)$ when compared to other drug-protein complexes with binding constants in the range of $10^{5}$ and $10^{6} \mathrm{M}^{-1}$ [32-34]. The reason for the low stability can be attributed to the presence of mainly hydrogen-bonding interaction or an indirect Protein-vitamin interaction through water molecules [25].

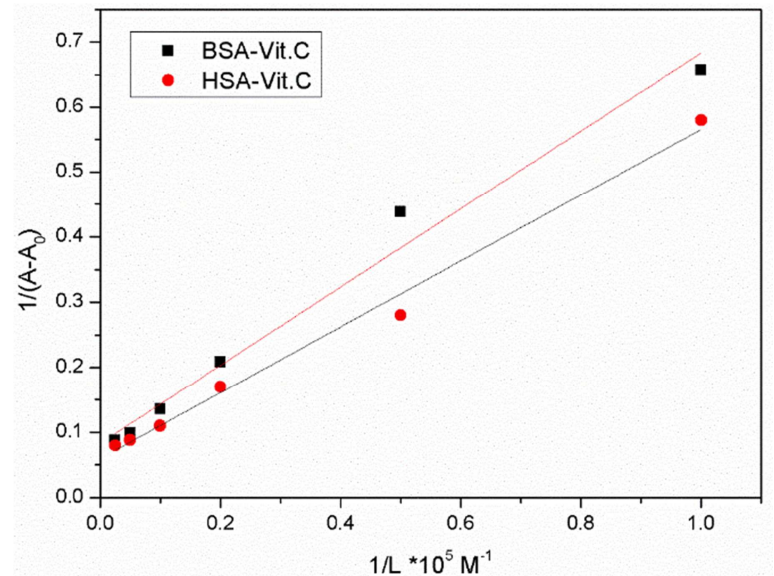

Figure 3. The plot of $1 /\left(A-A_{0}\right)$ vs. $1 / L$ for HSA and BSA with different concentrations of vitamin $C$.

\subsection{Fluorescence Quenching}

Fluorescence quenching studies to explore the binding interaction of drug ligands with proteins is considered as the best methodology [35]. This quenching resulted from the reduction of quantum yield of fluorescence from a fluorophore induced by a variety of molecular interaction with a quencher molecule [36, 37]. An Increase in the concentration of quencher will mask the fluorophore, result in reduction of emitted fluorescence from the fluorophore molecules. In ease of targeting specific location regarding the binding pattern of protein, we used different wavelength. Generally, the fluorescence of HSA and BSA comes from tryptophan, tyrosine and phenylalanine residues. During data recording at an excitation wavelength at $280 \mathrm{~nm}$, fluorescence of albumin was coming from both tryptophan and tyrosine residues, whereas $293 \mathrm{~nm}$ wavelength excited tryptophan residues only [38].

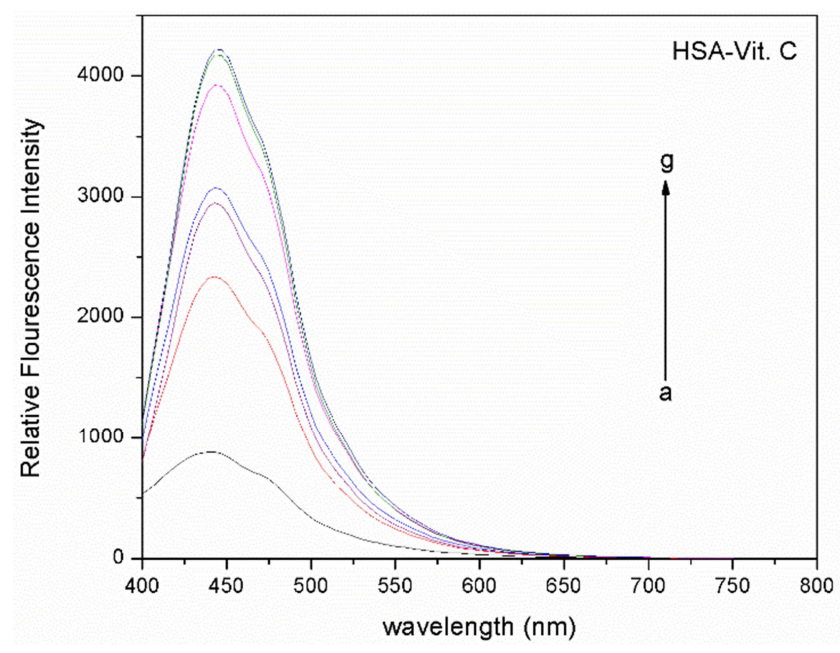

(a)

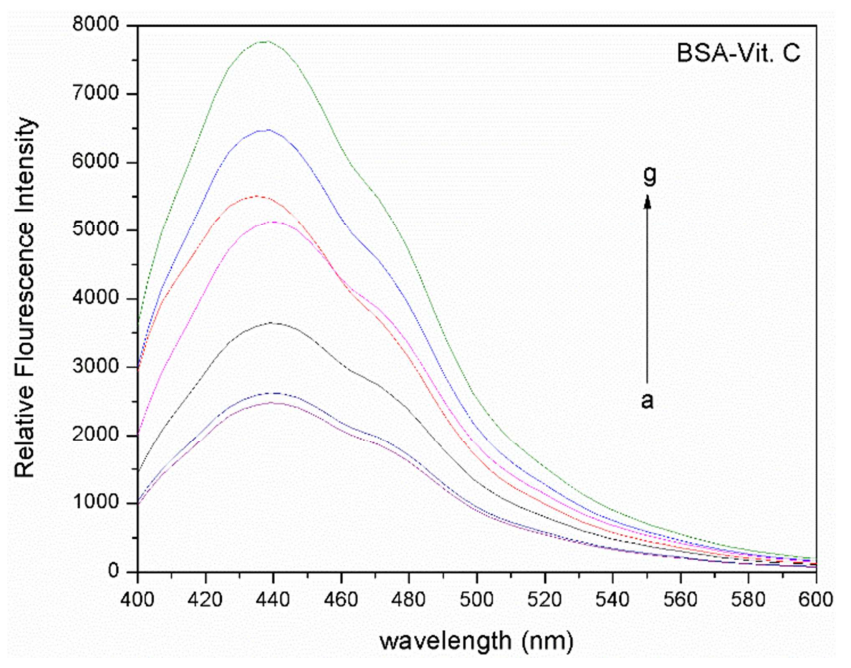

(b)

Figure 4. Fluorescence emission spectra in the absence and presence of vitamin $C$ ( $a=$ free (HSA (a), BSA (b), $b=1 \mathrm{mg} \cdot \mathrm{ml}^{-1}, c=2 m g \cdot m l^{-1}, d=5 \mathrm{mg} \cdot \mathrm{ml} l^{-1}$, $\left.e=10 \mathrm{mg} \cdot \mathrm{ml^{-1 }}, f=20 \mathrm{mg} \cdot \mathrm{ml}^{-1}, \mathrm{~g}=40 \mathrm{mg} \cdot \mathrm{ml}^{-1}\right)$.

Figure 4 represents the fluorescence spectra of HSA and 
BSA in combination with different concentrations of vitamin C. It was observed that fluorescence spectrum exhibiting the peak maximum at $460 \mathrm{~nm}$ for HSA-vitamin C complexes (Figure 4a) while the peak maximum appears to be at $440 \mathrm{~nm}$ for BSA-vitamin C complexes (Figure 4b). The fluorescence intensity decreases with increasing concentrations of vitamin C. This indicated that there was some alteration in the microenvironment of the fluorophore Trp-213 upon interaction of both proteins with vitamin $\mathrm{C}$.

Fluorescence quenching is usually classified into two types: dynamic quenching and static quenching. It can be distinguished by their different dependence on temperature and excited-state lifetime [39, 40]. For the dynamic quenching, higher temperatures will result in faster diffusion and larger amounts of collisional quenching. Therefore the quenching constant values will go up with the increase in temperature, but the reversed effect will be observed for static quenching [41]. To analyze the fluorescence quenching mechanism, the Stern-Volmer equation [42] was used:

$$
\frac{F_{0}}{F}=1+K_{s v}[L]=1+k_{q} \tau_{0}[L]
$$

where $\mathrm{F}_{0}$ and $\mathrm{F}$ are protein (HSA and BSA) fluorescence intensities in the absence and presence of quencher (Vitamins C); $\mathrm{k}_{\mathrm{q}}$ is the protein bimolecular quenching rate constant; $\tau_{0}$ is the average fluorescence lifetime of protein molecule without quencher (of the order of $10^{-8}[43]$ ); [L] is the concentration of quencher, $\mathrm{k}_{\mathrm{sv}}$ is Stern-Volmer fluorescence quenching constant.

As presented in Figure 5, the Stern-Volmer plot of both complexes fluorescence intensities. The two plots showed good linear relationship, suggesting the existence of a single type of quenching (dynamic or static) and/or a single binding site. The values of the fluorescence quenching constant determined applying Eq. (2) are equal to $\left(9.46 \times 10^{3}, 4.78 \times\right.$ $\left.10^{3}\right) \mathrm{L} \mathrm{mol}^{-1}$ for HSA/BSA-vitamin $\mathrm{C}$ respectively, both values are much lower than other $\mathrm{k}_{\mathrm{sv}}$ values for the similar systems signalized earlier in literature $[9,44]$. The values of $\mathrm{kq}$ which are equal to $\left(9.46 \times 10^{11}, 4.78 \times 10^{11}\right) \mathrm{L} \mathrm{mol}^{-1} \mathrm{~s}^{-1}$ for HSA/BSA-vitamin $\mathrm{C}$ respectively. These values confirms clearly the existence of static (diffusion- independent) mechanism of fluorescence quenching $[8,17,45]$.

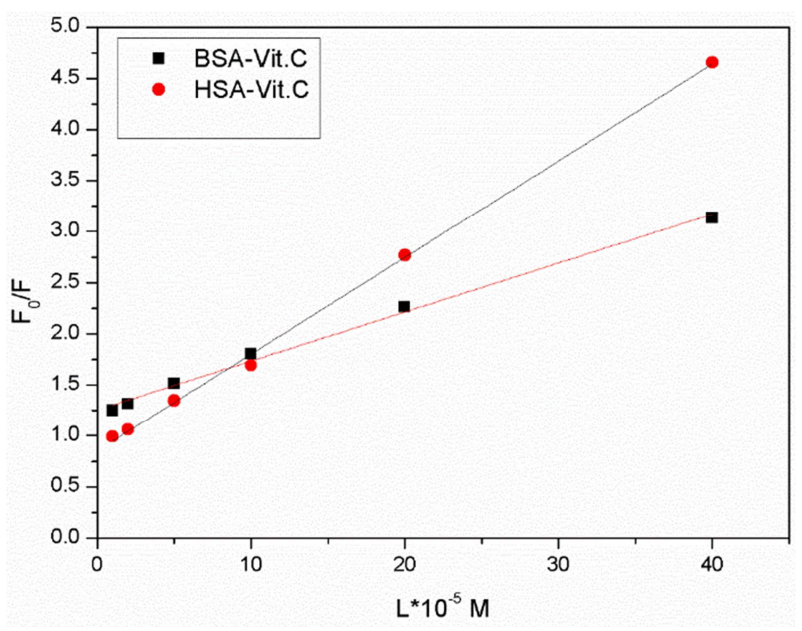

Figure 5. The Stern-Volmer plot for HSA/BSA-vitamin C complexes.
The calculated values of $\mathrm{kq}$ were greater than of the maximum dynamic quenching constant for various quencher with biopolymer $\left(2 \times 10^{10} \mathrm{~L} \cdot \mathrm{mol}^{-1} \cdot \mathrm{s}^{-1}\right)$ [46], this suggested that the fluorescence quenching was not the result of dynamic quenching, but the consequence of static quenching [47]. When static quenching is dominant, the modified SternVolmer equation could be used [48].

$$
\frac{1}{F_{0}-F}=\frac{1}{F_{0} K(L)}+\frac{1}{F_{0}}
$$

where $\mathrm{K}$ is the binding constant, a plot of $\frac{1}{F 0-F} \mathrm{vs} \frac{1}{L}$ is presented in Figure 6. The two plots are linear and have a slope of $\frac{1}{F 0 K}$ and intercept $\frac{1}{F 0}$ according to eq. (3). The values of $\mathrm{K}$ were found to be $\left(1.3 \times 10^{4} \mathrm{M}^{-1}, 1.6 \times 10^{4} \mathrm{M}^{-1}\right)$ for HSA/BSA-vitamin $\mathrm{C}$ respectively, which agrees well with the values obtained earlier by UV spectroscopy and supports the effective role of static quenching.

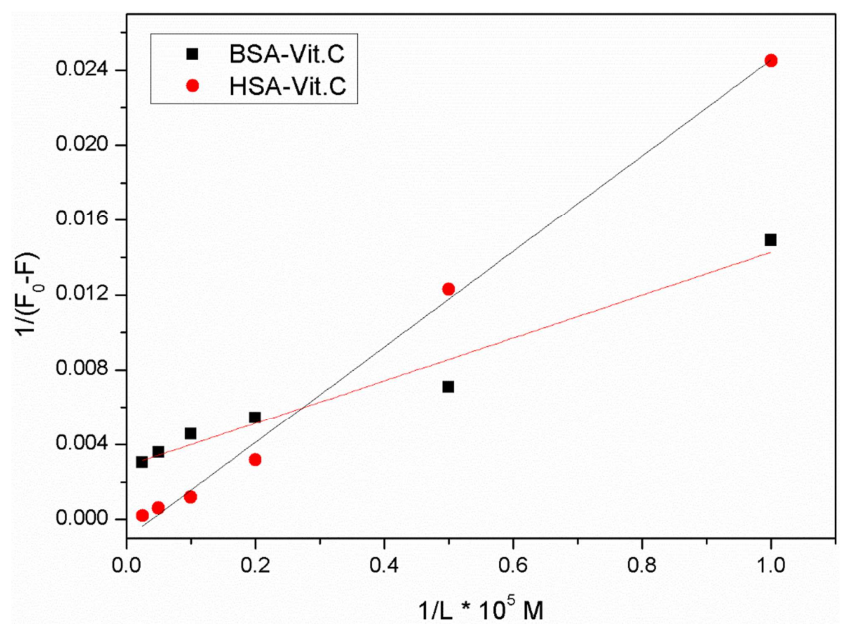

Figure 6. The plot of $1 /\left(F_{0}-F\right)$ vs. $1 / L \times 10^{5}$ for HSA/BSA-Vitamin $C$ complexes.

\section{Conclusions}

One of the crucial steps in developing a new and effective drug is studying and understanding its ability to bind to albumins, as serum albumin play a key role in the transport, distribution, metabolism and excretion of drugs molecules. In this work, the interaction between HSA/BSA-vitamin C was investigated by fluorescence and UV spectroscopic techniques. The results showed that the fluorescence of HSA and BSA would be quenched with the addition of vitamin C. This change was via static quenching. The calculated binding constants of the interaction of vitamin $\mathrm{C}$ with both proteins using both techniques showed a good agreement but the values were found to be relatively week.

The conclusions are important in the field of pharmacology and biochemistry and are helpful for understanding the effect of vitamin $\mathrm{C}$ on protein function during the blood transportation process. The clear and quantitative information on the nature of this study may provide some information for its rational use in clinical practice. 


\section{Acknowledgements}

This work is supported by the German Research Foundation DFG grant no. DR228/242

\section{References}

[1] Xiangrong Li, ab Gongke Wang, a Dejun Chena and Yan Lu, Binding of ascorbic acid and $\alpha$-tocopherol to bovine serum albumin: a comparative study. Molecular biosystem. 2014,10: 326-330.

[2] Guo X-J, Sun X-D, Xu S-K. Spectroscopic investigation of the interaction between riboflavin and bovine serum albumin. Journal of Molecular Structure. 2009, 931:55-9.

[3] Magdalena Makarska-Bialokoz, Investigation of the binding affinity in vitamin B12-Bovine serum albumin system using various spectroscopic methods, Spectrochimica Acta Part A: Molecular and Biomolecular Spectroscopy. 2017, 155 262269 .

[4] Houaria Merine, Lahcene Tennouga, Abderrezzak Mesli, Nafa Chafi, Kouider Medjahed, Kinetic Study of the Controlled Release of Procaine Grafted in Monomer and Copolymer Supports in both Homogeneous and Heterogeneous Medium, American Journal of Polymer Science. 2013, 3 (6): 99-106.

[5] Analytical profiles of drug substances and excipients, volume 26, 1990, Academic press, New Jersey, ISBN:0-12-260826-7.

[6] Adriana Fuliaş, Ionuţ Ledeţi, Gabriela Vlase, Călin Popoiu3, Alina Hegheș, Mihai Bilanin, Titus Vlase, Dorina Gheorgheosu, Marius Craina, Simona Ardelean, Dumitru Ferechide, Otilia Mărginean and Liana Moş, Thermal behaviour of procaine and benzocaine Part II: compatibility study with some pharmaceutical excipients used in solid dosage forms, Chemistry Central Journal. 2013, 7:140.

[7] Saqer Darwish, Sawsan E Abu sharkh, Mahmoud M M Abuhadid, Musa M Abu Teir, Sami A Makharza,, Spectroscopic study of propofol binding to human serum albumin, Biophysical Reviews and Letters. 2010, 5: 209-226.

[8] S. Nafisi, G. Sadeghi, A. Panahyab, Interaction of aspirin and vitamin $\mathrm{C}$ with bovine serum albumin, Journal of Photochemistry and Photobiology B: Biology. 2011, 105: 198-202.

[9] B. P. Kamat and J. seetharamappa, Spectroscopic Studies on the Mechanism of Interaction of Vitamin B12 with Bovine serum albumin, Journal of Photoscience. 2004, 11 (1): 29-33.

[10] H. Xu, Q. Leu, Spectroscopic Studies on the Interaction of Vitamin C with Bovine Serum Albumin, J Solution Chem. 2009, 38: 15-25.

[11] Tushar, K. M., Kalyan, S. G., Anirban, S., Swagata, D., The interaction of silibinin with human serum albumin:A spectroscopic investigation. Journal of Photochemistry and Photobiology A: Chemistry. 2008, 194: 297-307.

[12] Uversky, V., and Permykov, A., (2007): Methods in Protein Structure and Stability Analysis; Vibrational spectroscopy, Nova Science Publishers, Inc, Hauppauge, New York.

[13] Sirotkin, V. A., Zinatullin, A. N., Solomonov, B. N., Faizullin, D. A. and Fedotov, V. D., "Calorimetric and Fourier transform Infrared Spectroscopic Study of Solid Proteins Immersed in
Low Water Organic Solvents," Biochimica et Biophysica Acta, 2001, 1547: 359-369.

[14] Y. N. Chirgadze, O. V. Fedorov, N. P. Trushina," Secondary structure of $\mathrm{Na}^{+}, \mathrm{K}^{+}$-dependent adenosine triphosphatase," Biopolymers. 1975, 14: 679-694.

[15] Barth, A. (2000). The infrared absorption of amino acid side chains. Progress in Biophysics \& Molecular Biology. P:141173 .

[16] Buxbaum, E. (2007). Fundamentals of protein structure and function, Springer Science \& Business media, LLC.

[17] Zhang, Guowen; Que, Qingmin; Pan, Junhui; Guo, Jinbao, Study of the interaction between icariin and human serum albumin by fluorescence spectroscopy,, Journal of Molecular Structure. 2008, 881: 132-138.

[18] Li-Xia Xie, Hai-Long Wu, Chao Kang, Shou-Xia Xiang, Xiao-Li Yin, Hui-Wen Gu, Qi Zuo and Ru-Qin Yu, Quantitative Investigation of the Dynamic Interaction of Human Serum Albumin with Procaine Using a MultiwayCalibration, Annal. Methods. 2015, 7: 6552.

[19] S. Shahrakia, F. Shiria and H. Mansouri-Torshizib Biophysical and Molecular Docking Studies of Human Serum Albumin Interactions with a Potential Anticancer Complex, Biomacromol. J. 2016, 2: 65-77.

[20] Samira Ranjbar, Yalda Shokoohinia, Sirous Ghobadi, NooshinBijari, Saeed Gholamzadeh, Nastaran Moradi, Mohammad Reza Ashrafi-Kooshk, Abbas Aghaei, and Reza Khodarahmi, Studies of the Interaction between Isoimperatorin and Human Serum Albumin by Multi spectroscopic Method: Identification of Possible Binding Site of the Compound Using Esterase Activity of the Protein, The Scientific World Journal 2013, 1-13.

[21] Nanda RK, Sarkar N, Banerjee R. Probing the interaction of ellagic acid with human serum albumin: a fluorescence spectroscopic study. J Photochem Photobiol A Chem. 2007, 192:152-158.

[22] Colin, D. (2014). Introduction to Protein Structure Prediction. www.biostst.wisc.edu/bmi776/

[23] Cui Y, Wei Q, Park H Kl. Nanowire nanosensors for highly sensitive and selective detection of biological and chemical species. Science. 2001, 293: 1289-1292.

[24] Surewicz W K, Mantsch H H, Chapman D. Determination of protein secondary structure by Fourier transform infrared spectroscopy: A critical assessment. Biochemistry. 1993, 32: 389-394.

[25] Brewer S H, Glomm W R, Johnson M C. Probing BSA binding to citrate-coated gold nanoparticles and surfaces. Langmuir, 2005, 21: 9303-9307.

[26] Gao D J, Tian Y, Bi S Y. Studies on the interaction of colloidal gold and serum albumins by spectral methods. Spectrochim Acta Part A, 2005, 62: 1203-1208.

[27] Ojha B, Das G. The interaction of 5-(alkoxy) naphthalen-1amine with bovine serum albumin and its effect on the conformation of protein. J Phys Chem B, 2010, 114: 39793986.

[28] Bourassa P, Kanakis C D, Tarantilis P, et al. Resveratrol, genistein, and curcumin bind bovine serum albumin. J Phys Chem B, 2010, 114: 3348-3354. 
[29] Sawaki, K., and Kawaguchim, M. "Some Correlations between procaine-induced convulsions and monoamides in the spinal cord of rats". Japanese Journal of Pharmacology. 1989, 51: 369-376.

[30] Tayyebeh Madrakian, Habibollah Bagheri, Abbas Afkhami, Mohammad Soleimani, Spectroscopic and molecular docking techniques study of the interaction between oxymetholone and human serum albumin, J lumen. 2014, 155 218-225.

[31] Carter, D. C.; He, X.-M.; Munson, S. H.; Twigg, P. D.; Gernert, K. M.; Broom, M. B.; Miller, T. Y. Threedimensional Structure of Human Serum Albumin. Science 1994, 244: 1195-1198.

[32] Ahlbom A. A pooled analysis of magnetic fields and childhood leukaemia. Br. J. Cancer. 2000, 83: 692-698.

[33] International Agency for Research on Cancer 2002. Static and extremely low-frequency (ELF) electric and magnetic fields. IARC monographs on the evaluation of carcinogenic risks to humans, vol. 80 Lyon, France: IARC.

[34] National Radiological Protection Board (2001). ELF electromagnetic fields and the risk of cancer. Report of an Advisory Group on Non-ionising Radiation. Documents of the NRPB, vol 12 Chilton, Oxon, UK: NRPB.

[35] Lin, H., Lan, J., Guan, M., Sheng, F., Zhang, H. Spectroscopic investigation of interaction between mangiferin and bovine serum albumin, Spectrochimica Acta A, 2009, 73: 936-941.

[36] Connors, K. A., Binding Constants: the Measurement of Molecular Complex Stability, John Wiley \& Sons, New York, 1987.

[37] Bai, S., Jain, M. K., Berg, O. G. Contiguous binding of decylsulfate on the interface binding surface of pancreatic phospholipase A2, Biochemistry. 2008, 47: 2899-2907.

[38] Liedvogel M, Mouritsen H. Cryptochromes: a potential magnetoreceptor: what do we know and what do we want to know? J. R. Soc. Interface. 2010, 7: S147-S162.

[39] Byler, D. M., Susi, H. Examination of the secondary structure of proteins by deconvolved FTIR spectra, Biopolymers. 1986, 25: 469-487.

[40] Dockal, M., Chang, M., Carter, D. C., Rüker, F. Five recombinant fragments of human serum albumin-tools for the characterization of the warfarin binding site, Protein Science.
2000, 9: 1455-1465.

[41] Ahmed, A., Tajmir-Riahi, H. A., Carpentier, R. A quantitative secondary structure analysis of the $33 \mathrm{kDa}$ extrinsic polypeptide of photosystem II by FTIR spectroscopy, FEBS Letters. 1995, 363: 65-68.

[42] Ritz T, Adem S, Schulten K., "A model for photoreceptorbased magnetoreception in birds," Biophys. J. 2000, 78: 707- 718 .

[43] Shubhajit Paul, Alexey S. Kiryutin, Jinping Guo, Konstantin L. Ivanov, Jorg Matysik, Alexandra V. Yurkovskaya \& Xiaojie Wang, Magnetic field effect in natural cryptochrome explored with model compound, Scientific Reports. 2017, 7: 11892.

[44] Lakowicz, J. (2006): Principles of Fluorescence Spectroscopy, $3^{\text {rd }}$ ed, Springer Science+Business Media, USA.

[45] Lakowicz, J. R. (2002). Topics in fluorescence spectroscopy, Vol 5, Kluwer academic publishers.

[46] Brescoll, J., Daveluy, S., A Review Of Vitamin B12 In Dermatology. Annal Hematology. 2015, 16: 27-33.

[47] Sudlow, G., Birkett, D. J., Wade, D. N. Further characterization of specific drugbinding sites on human serum albumin, Molecular Pharmacology. 1976, 12: 1052-1061.

[48] Frei, B., England, L., Ames, B. N. Ascorbate is an outstanding antioxidant inhuman blood plasma, Proceeding of National Academy of Sciences. 1989, 86: 6377-6381.

[49] Krimm, S., Bandekar, J. Vibrational spectroscopy and conformation of peptides, polypeptides, and proteins, Advances in Protein Chemistry. 1986, 38: 181-364.

[50] Connors, K. A., Binding Constants: the Measurement of Molecular Complex Stability, John Wiley \& Sons, New York, 1987.

[51] Bai, S., Jain, M. K., Berg, O. G. Contiguous binding of decylsulfate on the interface binding surface of pancreatic phospholipase A2, Biochemistry. 2008, 47: 2899-2907.

[52] Bhattacharya, A. A., Curry, S., Franks, N. P. Binding of the general anesthetics propofol and halothane to human serum albumin, Journal of Biological Chemistry. 2000, 275: 3873138738 . 